\title{
Simultaneous recording of mechanical and intracellular electrical activity in human urinary bladder smooth muscle
}

\author{
A.J. VISSER and R. VAN MASTRIGT \\ Department of Urology-Urodynamics, Erasmus University Rotterdam, the Netherlands
}

Objective To elucidate the role of the membrane potential in human detrusor smooth muscle contraction, by simultaneously recording mechanical and intracellular electrical activity in muscle strips.

Materials and methods The agonists acetylcholine and carbachol were applied to induce a contraction on muscarinic receptor stimulation; to block the response, atropine was added to the bath. The $\mathrm{Ca}^{2+}$ necessary for activating the contractile machinery can be recruited via two pathways: release from intracellular stores or influx from the extracellular matrix. High potassium was applied to induce $\mathrm{Ca}^{2+}$ influx through voltage-sensitive $\mathrm{Ca}^{2+}$ channels.

Results There were significant changes in the force when agonist, antagonist and high potassium was adminis- tered. However, there were significant changes in membrane potential only when $\mathrm{KCl}$ was applied to the bath and not with muscarinic agonist or antagonist application. Activity in the form of spike potentials did not change significantly on applying any of the test substances.

Conclusion The present results indicate that the $\mathrm{Ca}^{2+}$ mobilized on $\mathrm{M}_{3}$ receptor stimulation originates primarily from intracellular stores, with no systematic changes in membrane potential. Atropine only caused a relaxation in muscle previously contracted by $\mathrm{M}_{3}$ receptor agonist stimulation; it had no effect on relaxed muscle strips.

Keywords Detrusor, muscle, force, electrophysiology, muscarinic, receptor

\section{Introduction}

The urinary bladder stores urine produced in the kidneys and expels it at a convenient moment under control of the parasympathetic nervous system [1,2]. In healthy human detrusor the neuromuscular transmission is predominantly cholinergic [3], although a partially atropine-resistant response is occasionally found [4]. The transmitter release causes an increase in free cytoplasmic $\mathrm{Ca}^{2+}$, activating the contractile machinery of the detrusor smooth muscle cells. There are two possible pathways for this rise in free cytoplasmic $\mathrm{Ca}^{2+}$ (Fig. 1): influx of $\mathrm{Ca}^{2+}$ from the extracellular matrix through voltage sensitive L-type $\mathrm{Ca}^{2+}$ channels, or release from intracellular stores [5]. The human detrusor expresses the muscarinic $\mathrm{M}_{3}$ receptor, which is coupled to a second-messenger system. Stimulation of the $\mathrm{M}_{3}$ receptor releases a $\mathrm{G}$ protein which mobilizes inositol (1,4,5)-trisphosphate $\left(\mathrm{IP}_{3}\right)$ [6], in turn releasing $\mathrm{Ca}^{2+}$ from the sarcoplasmic reticulum (SR) [7]. An increased intracellular $\mathrm{Ca}^{2+}$ concentration can also influence the release of $\mathrm{Ca}^{2+}\left(\mathrm{Ca}^{2+}\right.$-induced $\mathrm{Ca}^{2+}$ release) [8]. Thus far, the exact sequence of events on cholinergic activation is unclear. Observations in isolated guinea-pig

Accepted for publication 29 March 2000 detrusor cells suggest a crucial role for the extracellular $\mathrm{Ca}^{2+}$ influx in determining the extent of the rise of intracellular $\mathrm{Ca}^{2+}$ [9]. However, intracellular recordings in guinea-pig detrusor strips have shown that muscarinic stimulation can produce contractions with little change in membrane potential [10]. These results have been supported by experiments in isolated guinea-pig detrusor myocytes [5].

Studies in human urinary bladder have indicated that the passive force, spontaneous mechanical activity and contractions induced by muscarinic agonists and direct electrical stimulation depend on extracellular $\mathrm{Ca}^{2+}$ [11], implying $\mathrm{Ca}^{2+}$-channel activity. However, contractions have been induced by agonists in the absence of extracellular $\mathrm{Ca}^{2+}[12]$, suggesting that muscarinic agonists primarily use the second-messenger route. Evidence for a combined activation of both pathways upon cholinergic innervation has also been found $[1,13]$.

The role of the membrane potential in human detrusor muscle contraction is thus presently unclear. The cholinergic mode of activation does not require electrical activity to generate tension, but a role for electrophysiological phenomena in the contractile function of the human bladder cannot be excluded [5]. There are very few published reports of electrical activity recorded from intact urinary bladder smooth muscle of any large 


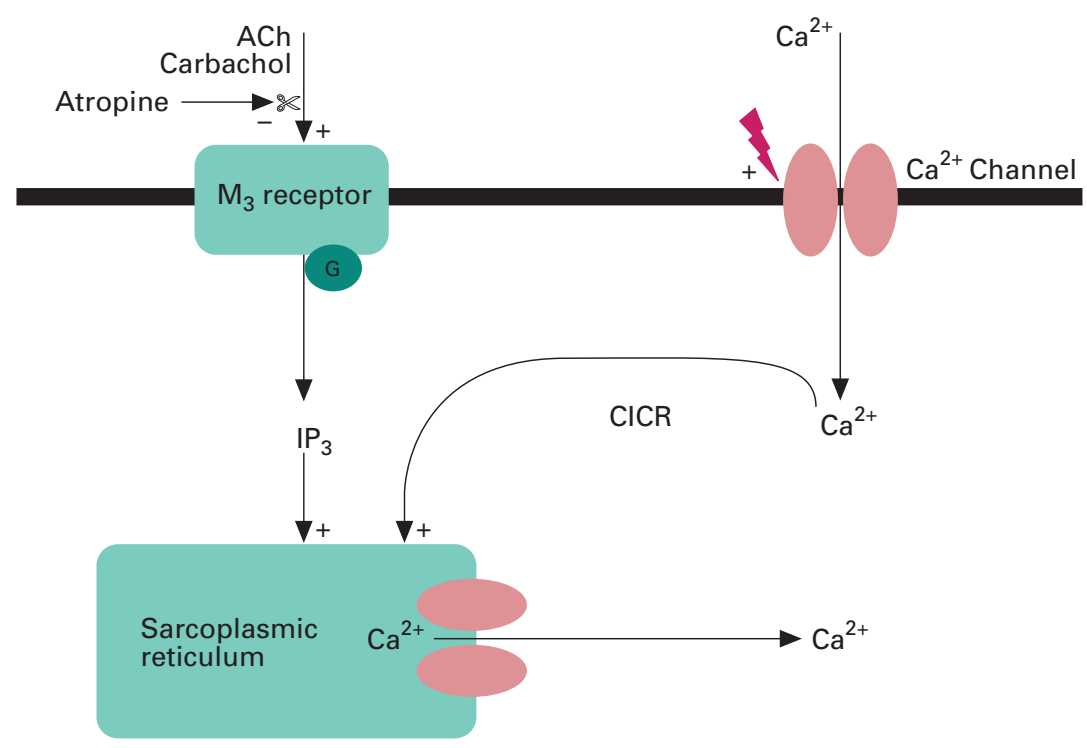

Fig. 1. A schematic representation of the two possible pathways to increase the intracellular $\mathrm{Ca}^{2+}$ concentration in human urinary bladder smooth muscle. ACh and carbachol (CCh) stimulate the muscarinic $\mathrm{M}_{3}$ receptor, triggering a second messenger system, i.e. G-protein $(\mathrm{G})$ and inositol $(1,4,5)$-trisphosphate $\left(\mathrm{IP}_{3}\right)$, that causes the release of $\mathrm{Ca}^{2+}$ from the sarcoplasmic reticulum (SR). Atropine blocks this response. $\mathrm{Ca}^{2+}$ influx through voltage-sensitive $\mathrm{Ca}^{2+}$ channels can induce $\mathrm{Ca}^{2+}$-induced $\mathrm{Ca}^{2+}$ release (CICR) from the intracellular stores.

mammal [14], including human [15]. This is probably because the detrusor muscle cells show continuous mechanical activity, and have an extensive extracellular matrix containing collagen and elastin [16], which makes it exceptionally difficult to impale these cells with electrodes.

Most information about human detrusor electrical activity has been obtained from single cells, using patch electrodes under current-clamp conditions [17]. Spontaneous action potentials were not normally observed. This lack of spontaneous activity may have been caused by intrinsically different behaviour of isolated cells, or by altered properties arising from the isolation procedure. Intracellular recordings in human detrusor strips [15] showed spontaneous activity, varying from single spike-shaped potentials to extensive bursts.

More insight in the role of the membrane potential could lead to a method to therapeutically and selectively suppress unstable detrusor contractions. In the present study, we simultaneously recorded mechanical and intracellular electrical activity in human urinary bladder strips. To induce contractions mediated by the $\mathrm{M}_{3}$ receptor, we applied both acetylcholine (ACh) and carbachol, as a possible difference in activation has been suggested [1]. Atropine was used to block the response. High potassium stimulation was used to induce $\mathrm{Ca}^{2+}$ influx through L-type $\mathrm{Ca}^{2+}$ channels.

\section{Materials and methods}

Detrusor biopsy samples were collected from 11 patients (one woman and 10 men, mean age 64 years, sD 11, range 44-81) with approval from the local ethical committee and with informed consent. The patients were undergoing surgery for bladder or prostate cancer and the tissue was collected using either cold-cup biopsy forceps (transurethral biopsies) or at open surgery (radical prostatectomy). Immediately after excision, the samples were stored in $0.9 \% \mathrm{NaCl}$; once outside the operating theatre, this solution was replaced by modified Krebs solution (composition in $\mathrm{mmol} / \mathrm{L}$ ) $1.8 \mathrm{CaCl}_{2}, 1.2$ $\mathrm{MgSO}_{4}, 118 \mathrm{NaCl}, 4.7 \mathrm{KCl}, 25.0 \mathrm{NaHCO}_{3}, 1.2 \mathrm{KH}_{2} \mathrm{PO}_{4}$, 11.0 glucose. By aerating the solution with a mixture of $95 \% \mathrm{O}_{2}$ and $5 \% \mathrm{CO}_{2}$, the $\mathrm{pH}$ was adjusted to 7.4 . The tissue was transferred to the laboratory within $10 \mathrm{~min}$ after excision, pinned down on Sylgard 184 (Dow Corning, Ithaca, NY, USA) and a muscle bundle of $\approx 2 \mathrm{~mm}$ long and $0.2 \mathrm{~mm}$ wide dissected. Three of the biopsy samples were stored at $4^{\circ} \mathrm{C}$ overnight before a muscle bundle was dissected. Connective tissue was removed mechanically.

\section{Tension recordings}

One side of the muscle bundle was pinned down in a 4-mL recording chamber with a Sylgard 184 base on the stage of an inverted microscope $(\times 40)$ which was gradually heated to $35^{\circ} \mathrm{C}$ using a modified thermostat. The free part of the muscle bundle was connected to the forceps of a force transducer (BAM4C, Scientific Instruments, Heidelberg, Germany). The muscle bundle was stretched minimally to enable microelectrode recordings.

\section{Electrophysiological recordings}

Recordings were made using borosilicate glass microelectrodes with a flexible tip (GC120F, Clark Electromedical Instruments, Pangbourne, Reading, UK). Filled with $3 \mathrm{~mol} / \mathrm{L} \mathrm{KCl}$, the electrodes had a 40-60 M $\Omega$ 
resistance. They were placed in an $\mathrm{Ag} / \mathrm{AgCl}$ pellet microelectrode holder connected to the input stage of a high-impedance capacitance-neutralizing amplifier (World Precision Instruments, Sarasota, FL, USA). An $\mathrm{Ag} / \mathrm{AgCl}$ electrode (outer diameter $2.0 \mathrm{~mm}$ ) in an agar bridge served as the reference electrode in the organ bath. The microelectrode potential was adjusted to zero before impaling a cell. At the end of the recording the microelectrode was removed from the cell and the zero level checked again. If the two values varied by $\leqslant 5 \mathrm{mV}$ the intracellular values of membrane potential were accepted. To minimize movement artefacts, the cells were speared in the longitudinal direction, at the side where the muscle bundle was pinned to the Sylgard.

Penetration of a cell was considered successful when the reference potential rapidly shifted to a more negative value of at least $-20 \mathrm{mV}$. The electrophysiological signal was amplified 10 times and low-pass filtered with a threshold frequency of $1 \mathrm{kHz}$ (Krohn-Hite Corporation, Avon, MA, USA). Both this signal and the signal from the force transducer were then converted (analogue to digital) at a sample rate of $2 \mathrm{kHz}$ (DAS1800, Keithley MetraByte, Taunton, MA, USA) using a locally developed sampling program, and stored digitally in a PC. The digitized force signal was filtered with a fourth-order Butterworth filter, using a threshold frequency of $2 \mathrm{~Hz}$, to reduce the noise level. The shape of the signal was not affected by the filtering process.

\section{Force induction}

To induce force, three different stimuli were used: the application of ACh (Sigma Chem. Co., St Louis, MO), carbachol (Pharmachemie B.V., the Netherlands) and $\mathrm{KCl}$. Atropine (Pharmachemie) was used to block the muscarinic receptor. Carbachol was dissolved in physiological salt solution and all other compounds in Krebs' solution. Stock solutions of ACh $(200 \mathrm{mmol} / \mathrm{L})$, carbachol $(1.4 \mathrm{mmol} / \mathrm{L})$, atropine $(1.4 \mathrm{mmol} / \mathrm{L})$ and $\mathrm{KCl}$ $(3 \mathrm{~mol} / \mathrm{L})$ were applied in random order to the bath in units of $0.01 \mathrm{~mL}$, resulting in minimum bath concentrations of $50 \mu \mathrm{mol} / \mathrm{L} \mathrm{ACh}, 3.4 \mu \mathrm{mol} / \mathrm{L}$ carbachol and $3.6 \mu \mathrm{mol} / \mathrm{L}$ atropine. These concentrations are considered supramaximal $[4,18,19]$. To induce depolarization of the membrane, a final $\mathrm{KCl}$ concentration of at least $12.2 \mathrm{mmol} / \mathrm{L}$ was used.

The bathing solution was refreshed constantly at $14 \mu \mathrm{L} / \mathrm{s}$, and the bath solution was renewed within $5 \mathrm{~min}$. However, difficulties in making long intracellular recordings were inherent to the type of preparation, therefore substances were often applied before total washout of the previous application. In those cases, the effective concentration was calculated using a standard concentration distribution formula; the final concentra- tions of the substances in the bath are given where appropriate. There were no significant correlations (Spearman's rank correlation) between the concentration of a substance and the resulting force, membrane potential $\left(V_{m}\right)$ or spike potential frequency $(P \geqslant 0.074)$, so the data were pooled. Krebs solution with no additions was used as a control for the application method.

\section{Data analysis}

The mean resting membrane potential of the impaled cell, $V_{\text {rest }}$, was calculated from the mean $V_{\text {rest }}$ during the $30 \mathrm{~s}$ before and $30 \mathrm{~s}$ immediately after the stimulus. Resting membrane potential values more negative than $-100 \mathrm{mV}$ were sometimes recorded. These results were considered to be an artefact, most likely resulting from bending of the electrode, and were therefore excluded from further analysis. The spike potential frequency was determined as the number of events per second (spikes/s) in the same periods as the mean $V_{\text {rest }}$ was determined, using specially developed software written in Matlab $\mathbb{R}$ 4.2c1 (The Mathworks Inc., Natick, MA, USA), as described previously [15].

Force values were read at the minimum level immediately before and at the maximum level after the stimulus. As values were not normally distributed, results are represented as median values and interquartile ranges. Relationships between the variables were assessed using Spearman's rank correlation test. The aim was to correlate the development of force and membrane potential activity and therefore no attempt was made to normalize force development. However, Spearman's rank correlation test was applied to three biopsies in which recording were obtained from several cells for a longer period, enabling the stimuli to be applied several times (more than five for the same stimulus). Each biopsy was tested separately and there were no significant correlations between membrane potential, spike-shaped potential frequency and force $(P \geqslant 0.107)$. Variables before and after drug application were compared using Wilcoxon's signed-rank test.

\section{Results}

The passive force exerted by the human detrusor strips at the start of the experiment was $270(420) \mu \mathrm{N}(n=11)$. This passive force was largely dependent on the amount of initial stretch placed on the bundle at the beginning of the experiment. Application of the muscarinic receptor agonists ACh and carbachol resulted in a significant increase in force $(P=0.002$ and 0.004 , respectively; Fig. 2), while the antagonist atropine resulted in a relaxation of the muscle strip $(P=0.003$; Fig. 2$)$. This relaxation only occurred if the tissue had contracted 

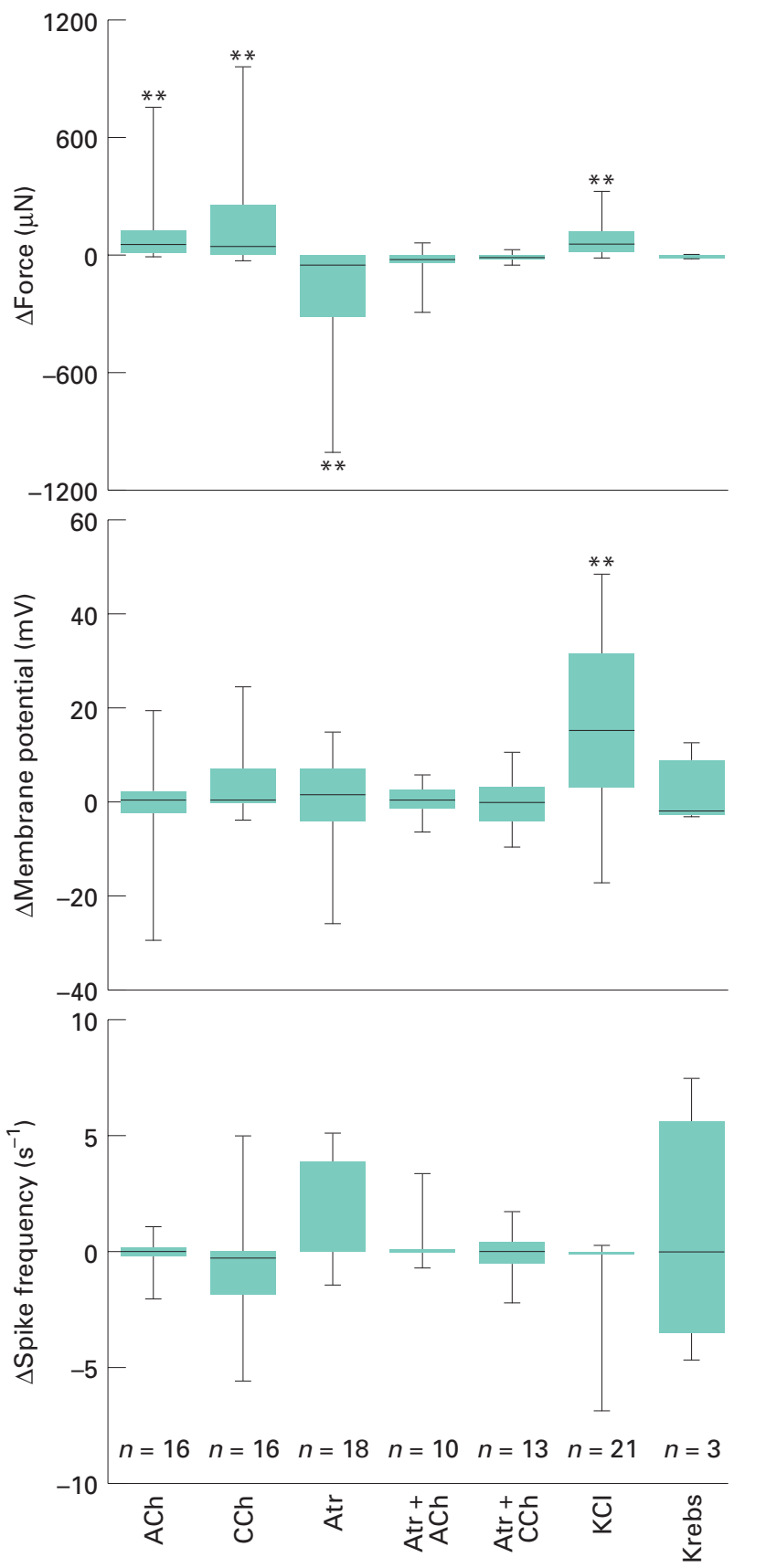

Fig. 2. The differences between values before and after applying substances represented in a box-plot. The values at 2.5, 25, 50 (median), 75 and 97.5 cumulative relative frequencies (centiles) are given. The numbers of events are shown at the bottom of the graph. $\mathrm{ACh}$, carbachol $(\mathrm{CCh})$ and $\mathrm{KCl}$ caused a significant increase in force. Atropine caused a relaxation of muscle tissue previously contracted by muscarinic receptor stimulation. Wilcoxon's signed-rank test was used to analyse the data; ${ }^{* *}$ indicates that $P \leq 0.005$; exact $P$ values are given in the text. The range of concentrations was: $\mathrm{ACh}, 50$ $110 \mu \mathrm{mol} / \mathrm{L}$; carbachol, 3.4-17 $\mu \mathrm{mol} / \mathrm{L}$; atropine, 3.6-29 $\mu \mathrm{mol} / \mathrm{L}$; $\mathrm{KCl}, 12.2-42 \mathrm{mmol} / \mathrm{L}$. previously upon agonist stimulation and had not yet fully relaxed. If no agonist had been applied, there was no relaxation of the tissue on applying antagonist. There was no significant change in force when ACh $(P=0.139)$ or carbachol $(P=0.203)$ were applied to the bath while atropine was present (Fig. 2). $\mathrm{KCl}$ increased the force significantly $(P<0.001$; Fig. 2$)$, while the application of Krebs solution to the bath had no effect $(P>0.999$, Fig. 2).

\section{Membrane potential and spike potential frequency}

The median value of the resting membrane potential of the detrusor muscle cells on impalement and with no drugs in the recording chamber, either at the beginning of the experiment $(n=10)$ or after a washout period of $\geqslant 60 \mathrm{~min}(n=4)$, was -45 (20) $\mathrm{mV}$ (total 14 samples). Any spontaneous excursion from the resting membrane potential was considered as membrane potential activity. Most of the impaled cells showed spontaneous activity in the form of spike-shaped potentials (Fig. 3) varying from single spikes to extensive bursts. The type of activity varied within and between different detrusor strips. There was a large variation in size and shape of the spikeshaped potentials between the biopsy samples and even within one cell. Figure 3 shows an example of spontaneous activity recorded; Fig. 3B shows parts of the recording in Fig. $3 \mathrm{~A}$ at a faster time scale. Apart from spike-shaped potentials, fast, small depolarizations (Fig. $3 \dagger$ ) and prolonged depolarizations (Fig. $3 \ddagger$ ) were observed.

The response to the applied substances varied greatly and Fig. 4 shows examples; ACh was applied to the bath, resulting in an increase in force (upper trace). The $V_{m}$ (lower trace) was quiet and on applying ACh there was no change in activity, although there was a small hyperpolarization. Figure 4B shows an example of carbachol application; there was a brief increase in membrane potential activity in the form of fast, small depolarizations after carbachol application, before an increase in force. Eventually the $V_{m}$ quietened again, before the force reached its peak. Figure $5 \mathrm{~A}$ shows an example of a change in spike-shaped potential activity after applying atropine. Changes in membrane potential activity occurred in $11 \%$ of the applications of carbachol and $26 \%$ of the ACh applications. The differences in $V_{m}$ $(P=0.959, \quad P=0.148, \quad P=0.320)$ or spike potential frequency $(P=0.133, P=0.281, P=0.079)$ before and after application of $\mathrm{ACh}$, carbachol and atropine, respectively, were not significant (Fig. 2). Likewise, when ACh or carbachol were applied to the bath in the presence of atropine, there were no significant changes in $V_{\mathrm{m}}(P \geqslant 0.683$; Fig. 2$)$, or spike frequency $(P \geqslant 0.600$, Fig. 2). A significant change in $V_{m}$ could only be 


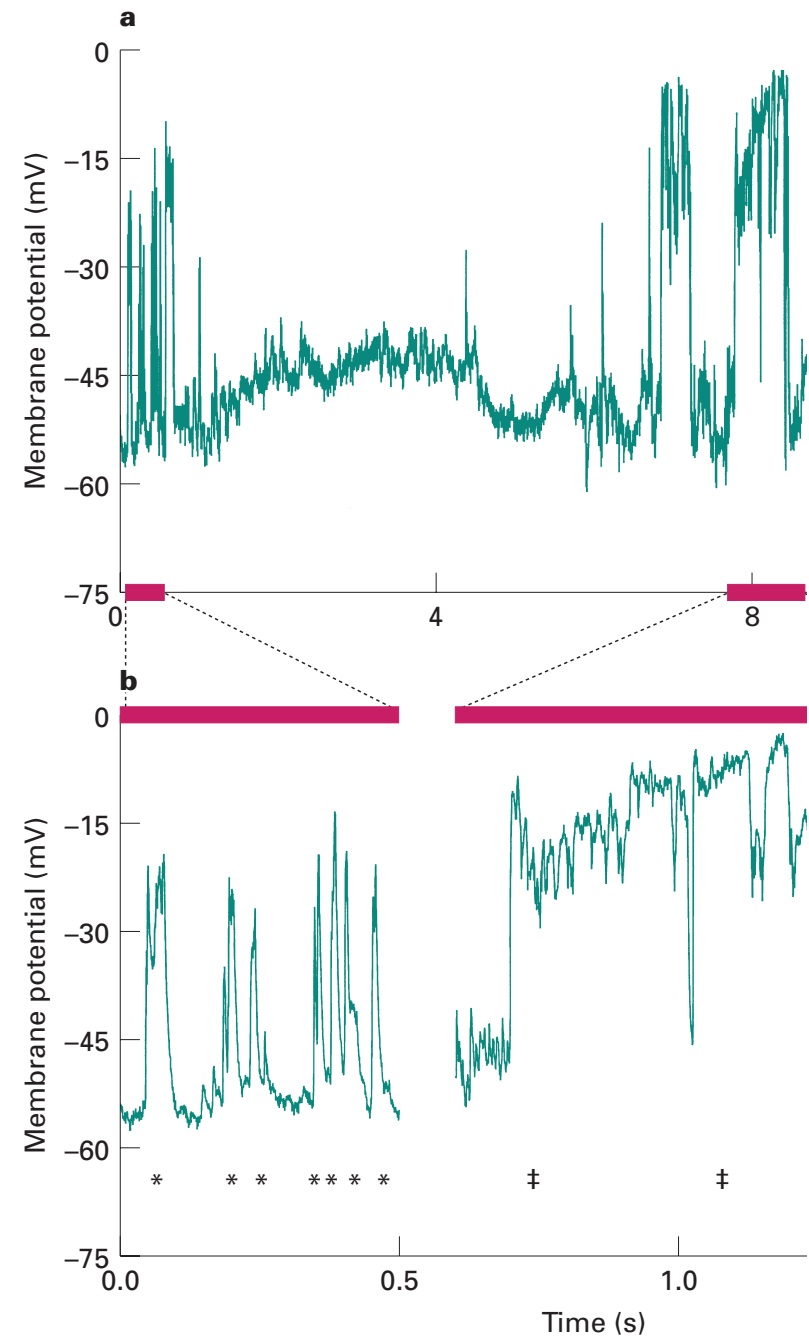

Fig. 3. A typical pattern of spontaneous activity in human detrusor muscle strips consisting of spontaneous spike shaped-potentials and quiescent periods. Two periods indicated by bars on the $\mathrm{X}$-axis are shown in $\mathbf{b}$ on a faster time scale. ${ }^{*}$ indicates spike-shaped potentials; łindicates prolonged depolarizations; $\dagger$ indicates fast, small depolarizations.

measured when the $\mathrm{K}^{+}$concentration was raised $(P=0.003$; Fig. 2). The membrane depolarized rapidly (Fig. 5B). In a few cases, there was a change in spike potential activity, but these changes were not significant $(P=0.683$, Fig. 2$)$. Adding Krebs to the bath caused no differences ( $P>0.999$; Fig. 2).

Correlation between $V_{m}$, spike potential frequency and force

Spearman's ranks correlation test showed a significant correlation between the $V_{m}$ of the impaled cell and the average force level in the human urinary bladder smooth muscle strip before substances were applied $\left(r_{\mathrm{s}}=-0.231, P=0.023, n=97\right)$, but not between the spike potential frequency and force $\left(r_{\mathrm{s}}=0.038\right.$, $P=0.708, n=97)$. Applying muscarinic agonists, the antagonist or $\mathrm{KCl}$ to the bath did not result in either a significant correlation between the change in $V_{m}$ and the change in force, or between the latter and the change in spike potential frequency $(P \geqslant 0.246$ and $P \geqslant 0.056$, respectively).

\section{Discussion}

Simultaneous recordings of mechanical and intracellular electrical activity are necessary to elucidate the role of the membrane potential in human detrusor contraction. In the present study, the resting membrane potential was very variable. Values more negative than $-100 \mathrm{mV}$ were probably caused by bending the electrode, as such values would require a physiologically unrealistic intracellular $\mathrm{K}^{+}$concentration. Such bending artefacts may have been caused by the constant mechanical activity of the detrusor cells and these values were excluded from further analysis.

There was a negative correlation between the $V_{m}$ of the impaled cell and the average force level of a strip: the higher the resting force, the more depolarized the $V_{m}$. This agrees with the results obtained in rabbit detrusor [20], where stretch of the muscle strip resulted in a depolarization of the membrane potential.

As in guinea-pig urinary bladder strips [21,22], human multicellular preparations showed spontaneous fluctuations from the resting membrane potential in the form of spike-shaped potentials. The electrical activity was asynchronous within one muscle bundle, probably because of the relatively poor cell-to-cell coupling. As was found previously in human [15] and in rabbit [20], there was a large variation in size and shape of the spikeshaped potentials; they were not 'all-or-none' events, unlike action potentials. Therefore, we do not use the term action potential for these events. However, we assume that the spike-shaped potentials fulfil a similar role to action potentials. Additionally, another form of spontaneous activity was recorded, i.e. fast, small depolarizations. These may correspond to the spontaneous transient depolarizations which have been recorded in guinea-pig urethra [23]. In that preparation, the spontaneous transient depolarizations are the result of spontaneous release of $\mathrm{Ca}^{2+}$ from intracellular stores, which activates $\mathrm{Ca}^{2+}$-activated $\mathrm{Cl}^{-}$-channels [23]. Furthermore, there were prolonged depolarizations that may be equivalent to the slow waves recorded in the previous study [23]. Hashitani and Edwards [23] suggested that these slow waves are a summation of spontaneous transient depolarizations. From the present study we cannot draw a similar conclusion, although it is 

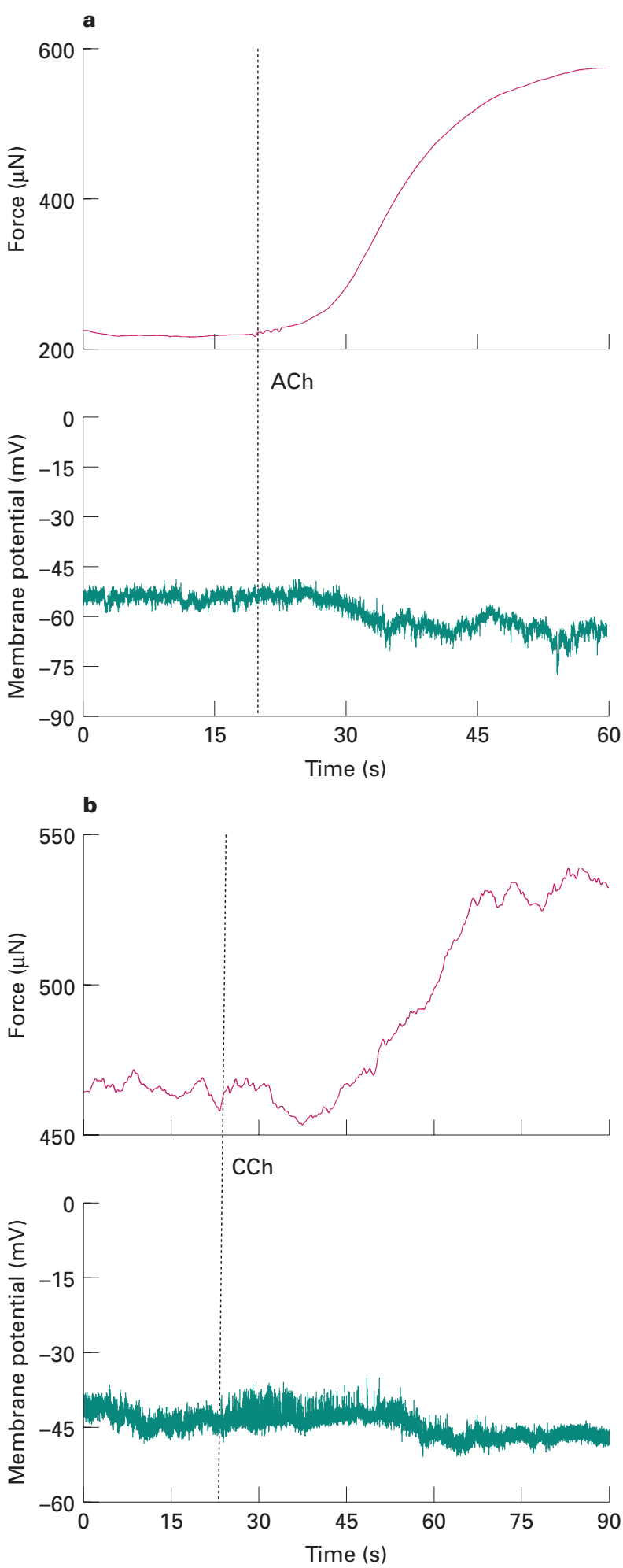

Fig. 4. A typical example of the response of human urinary bladder muscle to A, acetylcholine and B, carbachol. The upper traces show force and the lower traces the membrane potential. In A, there was a slight hyperpolarization and no change in membrane potential activity on stimulation $(26 \mu \mathrm{mol} / \mathrm{L})$ and in $\mathrm{B}$ there was a transient increase in membrane potential activity on stimulation $(3.5 \mu \mathrm{mol} / \mathrm{L})$ possible that the prolonged depolarizations are the result of the release of intracellular $\mathrm{Ca}^{2+}$.

Stimulation of the muscarinic $\mathrm{M}_{3}$ receptor with ACh or carbachol resulted in an increase in force, but had no systematic effect on the membrane potential. In only $37 \%$ of all agonist applications was there an effect on $V_{m}$ activity. This suggests that the primary route to mobilize $\mathrm{Ca}^{2+}$ on stimulation of the $\mathrm{M}_{3}$ receptor is through $\mathrm{Ca}^{2+}$ release from intracellular stores. Similar results were obtained in rabbit detrusor [20]. In contrast, Seki et al. [24] reported a depolarization of the membrane with a significant increase in spike discharge in guinea-pig bladder. However, in the same tissue an increase in the spike frequency with no significant change in membrane potential on carbachol application was also reported [25]. Likewise, Wu and Fry [26] showed that muscarinic agonists can generate a rise in intracellular $\mathrm{Ca}^{2+}$ independent of changes in membrane potential in guinea-pig detrusor myocytes. In the present study, the frequency of the spontaneous spike-shaped potentials recorded in the cells did not change significantly upon any stimulus. It is therefore likely that in human detrusor this feature is neither regulated by the muscarinic receptor, nor by the intracellular $\mathrm{Ca}^{2+}$ concentration.

The overall mechanical activity of the muscle cells in the preparation showed no correlation with the membrane potential or the spike potential frequency recorded in the impaled cell. There are two possible explanations for this: it is possible that not all cells were recruited during contraction. This would be plausible for the resting tonus. However, with the supramaximal stimuli used, all cells were expected to be contracted, and as recordings were from cells at the surface layer, it is unlikely that the stimuli did not reach the impaled cell. It is therefore more likely that there is a dissociation between membrane potential activity and contractile activity at the cellular level.

There were no significant differences between stimulation with carbachol or ACh, when applied exogenously, as was found earlier by Anderson et al. [27]. However, we cannot exclude the possibility that stimulation of the $\mathrm{M}_{3}$ receptor with exogenously applied $\mathrm{ACh}$ and transmitter released from nerves has different effects on the increase in free intracellular $\mathrm{Ca}^{2+}$.

Previous reports have suggested that muscarinic receptor stimulation may lead to both intracellular $\mathrm{Ca}^{2+}$ release and extracellular $\mathrm{Ca}^{2+}$ influx. Husted et al. [28] showed that electrically induced contractions are abolished $10 \mathrm{~min}$ after omitting $\mathrm{Ca}^{2+}$ from the bath solution, suggesting a role for extracellular $\mathrm{Ca}^{2+}$ on nervous stimulation of the human detrusor. The time elapsed between omitting $\mathrm{Ca}^{2+}$ from the bath solution and the abolition of contractions might also indicate that the intracellular stores were depleted and could not be 

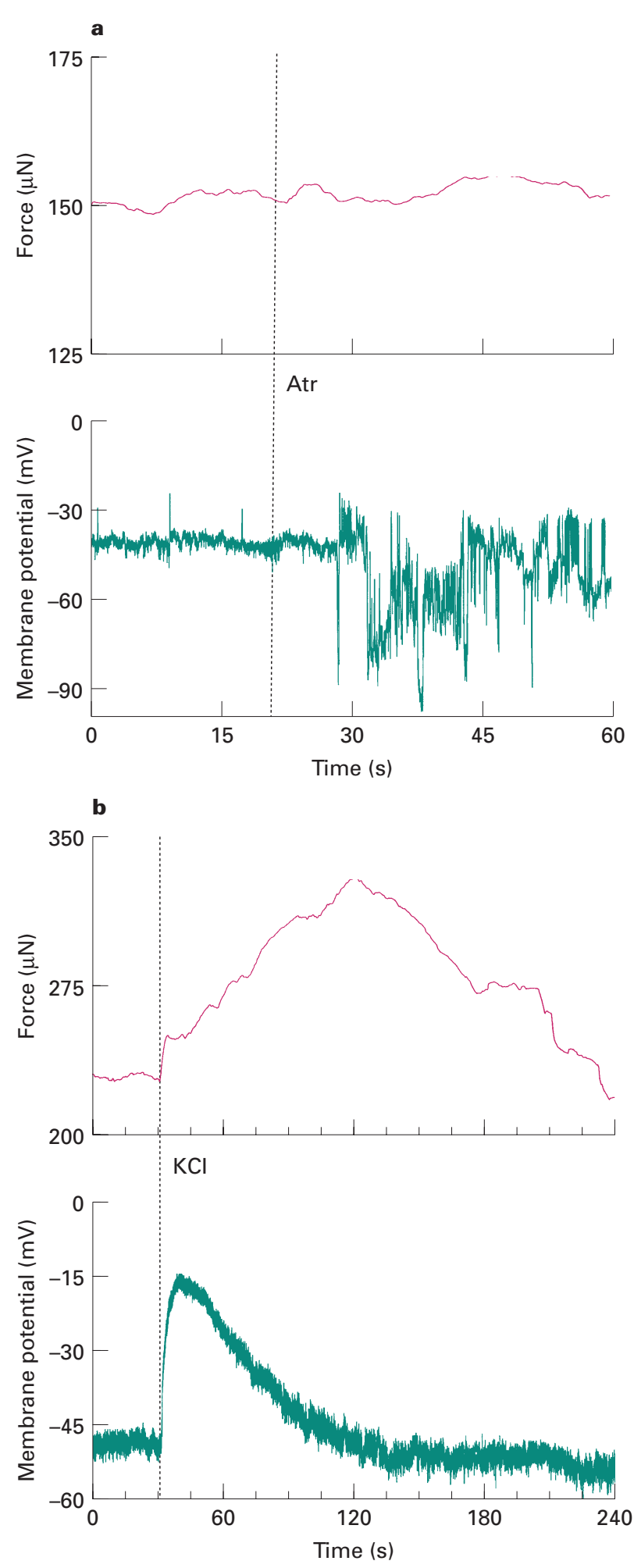

Fig. 5. An example of a response of human urinary bladder muscle to $\mathrm{A}$, atropine and $\mathrm{B}, \mathrm{KCl}$. The upper trace shows the force and the lower trace the membrane potential. In A, there was a change in membrane potential activity on stimulation $(21 \mu \mathrm{mol} / \mathrm{L})$ and in $\mathrm{B}$ there was a rapid, prolonged and large depolarization of the membrane potential on stimulation $(37 \mathrm{mmol} / \mathrm{L})$. Fig. $4 \mathrm{~A}$ and $5 \mathrm{~B}$ were recorded in the same cell. refilled with $\mathrm{Ca}^{2+}$ from the extracellular matrix. Furthermore, they showed that preventing $\mathrm{Ca}^{2+}$ influx into the cell through L-type $\mathrm{Ca}^{2+}$ channels reduced the contraction induced by endogenously released ACh by $\approx 40 \%$ [28]. Moreover, a role for $\mathrm{Ca}^{2+}$ influx via L-type $\mathrm{Ca}^{2+}$ channels was also suggested in response to carbachol [1]. In contrast, Maggi et al. [12] showed that carbachol mobilizes $\mathrm{Ca}^{2+}$ in the absence of extracellular $\mathrm{Ca}^{2+}$ from a caffeine- and procainesensitive intracellular store. A combination of both pathways for $\mathrm{Ca}^{2+}$ mobilization on carbachol stimulation has also been reported: for small contractions almost all of the $\mathrm{Ca}^{2+}$ is derived from the SR, for intermediate contractions the $\mathrm{Ca}^{2+}$ is recruited from both stores evenly, and for maximal contractions most $\mathrm{Ca}^{2+}$ is extracellular [13]. Based on this theory, $\mathrm{Ca}^{2+}$ from both sources would be expected to be involved in the present measurements, as the strips were stimulated supramaximally. Although we cannot exclude a combination of pathways, the present results support $\mathrm{Ca}^{2+}$ mobilization primarily from the intracellular stores.

Applying the $\mathrm{M}_{3}$ receptor antagonist atropine resulted in a significant relaxation of the smooth muscle tissue, but only if it was previously contracted by agonist stimulation and had not yet fully relaxed.

Depolarization of the membrane potential with high potassium levels, presumably through stimulation of the L-type $\mathrm{Ca}^{2+}$ channel, resulted in the development of significant force. There was no correlation between the magnitude of the depolarization and the developed force. This may possibly have occurred because the contraction of the detrusor strip was not generated only by the cell from which the recording was made.

A tight coupling between membrane potential activity and mechanical activity was reported in guinea-pig detrusor, using the sucrose-gap method [22]. In human detrusor, as in rabbit detrusor, this was not found. Differences between species in functional and contractile behaviour of bladder muscle have been reported previously [3].

We conclude that in human urinary bladder smooth muscle on stimulation of the muscarinic $M_{3}$ receptor, electrical and mechanical activity are not correlated. This suggests that the primary route for mobilizing $\mathrm{Ca}^{2+}$ is then through $\mathrm{Ca}^{2+}$ release from intracellular stores, with no changes in membrane potential.

\section{Acknowledgements}

We thank Prof. Dr Alison F. Brading for her valuable help and advice on the manuscript. This study was supported by the Dutch Kidney Foundation (C94.1370). We thank the urologists of the University Hospital Rotterdam (AZR) for providing the biopsy samples. 


\section{References}

1 Fovaeus M, Andersson K-E, Batra S, Morgan E, Sjögren C. Effects of calcium, calcium channel blockers and Bay $\mathrm{K}$ 8644 on contractions induced by muscarinic receptor stimulation of isolated bladder muscle from rabbit and man. J Urol 1987; 137: 798-803

2 Kinder RB, Mundy AR. Atropine blockade of nervemediated stimulation of the human detrusor. $\mathrm{Br} J$ Urol 1985; 57: 418-21

3 Sibley GNA. A comparison of spontaneous and nervemediated activity in bladder muscle from man, pig and rabbit. J Physiol 1984; 354: 431-43

4 Sjögren C, Andersson K-E, Husted S, Mattiasson A, MollerMadsen B. Atropine resistance of transmurally stimulated isolated human bladder muscle. J Urol 1982; 128: 1368-71

5 Fry $\mathrm{CH}, \mathrm{Wu} \mathrm{C}$. The cellular basis of bladder instability. $\mathrm{Br}$ J Urol 1998; 81: 1-8

6 Iacovou JW, Hill SJ, Birmingham AT, Bates CP. Calcium dependence and inositol phosphate accumulation in human detrusor smooth muscle. Neurourol Urodyn 1989; 8: 418-9

7 Eglen RM, Reddy H, Watson N, Challiss RAJ. Muscarinic acetylcholine receptor subtypes in smooth muscle. Trends Pharmacol Sci 1994; 15: 114-9

8 Ganitkevich VY, Isenberg G. Contribution of $\mathrm{Ca}^{2+}$-induced $\mathrm{Ca}^{2+}$-release to the $\left[\mathrm{Ca}^{2+}\right]_{\mathrm{i}}$ transients in myocytes from guinea-pig urinary bladder. J Physiol 1992; 458: 119-37

9 Ganitkevich VY, Isenberg G. Depolarization-mediated intracellular calcium transients in isolated smooth muscle cells of guinea-pig urinary bladder. J Physiol 1991; 435: 187-205

10 Fujii K. Evidence for adenosine triphosphate as an excitatory transmitter in guinea-pig, rabbit and pig urinary bladder. J Physiol 1988; 404: 39-52

11 Andersson K-E, Forman A. Effects of calcium channel blockers on urinary tract smooth muscle. Acta Pharmacol Toxicol 1986; 58: 193-200

12 Maggi CA, Guiliani S, Patacchini R et al. Multiple sources of calcium for contraction of the human urinary bladder muscle. Br J Pharmacol 1989; 98: 1021-31

13 Masters JG, Neal DE, Gillespie JI. The effects of thapsigargin on agonist-induced contractile responses in isolated human detrusor smooth muscle. Proc Physiol Soc 1997; 507P: 111P-2P

14 Callahan SM, Creed KE. The effects of oestrogens on spontaneous activity and responses to phenylephrine of the mammalian urethra. J Physiol 1985; 358: 35-46

15 Visser AJ, van Mastrigt R. Intracellular recording of spontaneous electrical activity in human urinary bladder smooth muscle strips. Arch Physiol Biochem 1999; 107: $257-70$
16 Zimmern PE, Lin VK, McConnell JD. Smooth muscle physiology. Urol Clin North Am 1996; 23: 211-9

17 Montgomery BSI, Fry CH. The action potential and net membrane currents in isolated human detrusor smooth muscle cells. J Urol 1992; 147: 176-84

18 Maggi CA, Giuliani S, Patacchini R et al. Potent contractile activity of endothelin on the human isolated urinary bladder. Br J Pharmacol 1989; 96: 755-7

19 Rubinstein R, Nissenkorn I, Cohen S. A study of the contractile response to acetylcholine in human ileal and detrusor muscle: origin of the low efficacy of acetylcholine. Eur J Pharmacol 1986; 123: 145-53

20 Ursillo RC. Electrical activity of the isolated nerve-urinary bladder strip preparation of the rabbit. Am J Physiol 1961; 201: 408-12

21 Creed KE. Membrane properties of the smooth muscle membrane of the guinea-pig urinary bladder. Pflügers Arch 1971; 326: 115-26

22 Mostwin JL. The action potential of guinea-pig bladder smooth muscle. J Urol 1986; 135: 1299-303

23 Hashitani H, Edwards FR. Spontaneous and neurally activated depolarizations in smooth muscle cells of the guinea-pig urethra. J Physiol 1999; 514: 459-70

24 Seki N, Karim OMA, Mostwin JL. Effect of pinacidil on the membrane electrical activity of guinea-pig detrusor muscle. J Pharmacol Exp Ther 1992; 263: 816-22

25 Hashitani H, Suzuki H, Kamazawa J. Effects of Y-26763, a novel K-channel opener, on electrical responses of smooth muscles in the guinea pig bladder. J Urol 1996; 155: 1454-8

$26 \mathrm{Wu} \mathrm{C}$, Fry $\mathrm{CH}$. The role of the L-type $\mathrm{Ca}^{2+}$ channel in cholinergic pathways in guinea-pig detrusor smooth muscle. J Physiol 1997; 499: 7P-8P

27 Anderson K-E, Holmquist F, Fovaeus M, Hedlund H, Sundler R. Muscarinic receptor stimulation of phosphoinositide hydrolysis in the human isolated urinary bladder. J Urol 1991; 146: 1156-9

28 Husted S, Sjögren C, Andersson K-E. Direct effects of adenosine and adenine nucleotides on isolated human urinary bladder and their influence on electrically induced contractions. J Urol 1983; 130: 392-8

\section{Authors}

A.J. Visser, PhD Student.

R. van Mastrigt, PhD.

Correspondence: A.J. Visser, Department of UrologyUrodynamics, Room EE 16-30, Erasmus University Rotterdam, 3000 DR Rotterdam, The Netherlands. E-mail: visser@udn.fgg.eur.nl 